\title{
The Oral Health of Patients with DiGeorge Syndrome (22q I I) Microdeletion: A Case Report
}

\author{
Estephania Candelo $\mathbb{1 D}^{1-3}$ \\ Maria Alejandra Estrada- \\ Mesa $^{4}$ \\ Adriana Jaramillo $\mathbb{D}^{4}$ \\ Carlos Humberto Martinez- \\ Cajas (D) ${ }^{4}$ \\ Julio Cesar Osorio ${ }^{4}$ \\ Harry Pachajoa (DD ${ }^{1,2}$ \\ 'Congenital Abnormalities and Rare Disease \\ Centre (CIACER), Cali, Colombia; \\ ${ }^{2}$ Genetics Department, Fundacion Valle del \\ Lili, Cali, Colombia; ${ }^{3}$ Centro de \\ Investigaciones Clínicas, Fundacion Valle del \\ Lili, Cali, Colombia; ${ }^{4}$ Institución Universitaria \\ Colegios de Colombia (UNICOC), Cali, \\ Colombia
}

Background: DiGeorge syndrome (DG) is a genetic disorder associated with 22q11 deletion. It involves various phenotypes, including craniofacial abnormalities, congenital heart disorders, endocrine dysfunction, cognitive deficits, and psychiatric disorders. Cases commonly involve multiple anomalies. However, little is known about the condition of the oral cavity in this disorder, although palate fissure, abnormal mandible, malocclusion, and tooth hypoplasia have been identified. We aimed to determine the odontological features of patients with 22q11.2 microdeletion, in relation to gingival health and oral hygiene. We report the systemic manifestations of nine patients and results of oral evaluation of two patients. In the oral examination, oral hygiene and gingivitis were evaluated.

Case Presentation: In terms of the systemic manifestations, we found high frequencies of low weight and height at birth. In terms of the oral manifestations, both examined patients presented malocclusion, enamel hypoplasia, dental crowding, anodontia, and healthy periodontium.

Conclusion: Although DG has been documented to involve periodontium disease, the patients in this study exhibited more dental manifestations such as enamel defects, misalignment between the teeth and the two dental arches, anodontia, and dental crowding. As such, a multidisciplinary approach combining dentistry and healthcare is recommended in this case.

Keywords: DiGeorge syndrome 22q11.2 deletion, oral manifestations, facial dysmorphism, case report

\section{Background}

DiGeorge syndrome (OMIM: 188,400) is a congenital disorder, all the clinical manifestations of which are related to the genes surrounding the 22q11.2 region. ${ }^{1}$ It is one of the most frequent rare disorders, resulting in an embryological defect involving the third and fourth branchial arches. ${ }^{1,2}$ The approximate frequency is around 1 per 4000 newborns, reaching up to 1 in 1000 in certain populations. ${ }^{3-6}$ The majority of cases result from heterozygous chromosomal deletion in the abovementioned region. The size of the deleted chromosomal region has been reported in different series to be around 0.7-3 million base pairs ${ }^{7}$ As a result of this deletion, several genes are lost, including HIRA protein (HIRA), T-box 1 protein (TBX1), Catechol-O-methyltransferase (COMT), and Recombinant Human Crkl (CRKL). ${ }^{8-10}$ These genes are related to the formation and development of the pharyngeal arches (PA) and the migration of neural crest cells; for that reason, the genetic disruption of these genes alters various structures, resulting in conditions such as conotruncal cardiac anomalies, thymus hypoplasia, hypocalcemia
Correspondence: Estephania Candelo Email ecandelo@icesi.edu.co 
resulting from lack of development of the parathyroid glands, cognitive deficits, frequent infections, and autoimmune disorders. ${ }^{1}$

This syndrome presents a variable and broad phenotype, which can include craniofacial abnormalities (CA), congenital heart diseases, endocrine dysfunction, cognitive deficits, and psychiatric disorders. ${ }^{10}$ The CA in DiGeorge Syndrome (DG) include micrognathia or abnormal mandible, broad nasal base, bulbous nasal tip, upslanting palpebral fissure, midface hypoplasia, low-set, and posteriorly rotated ears, ocular hypertelorism, vertical maxillary excess, overt cleft palate, and submucosal cleft palate. ${ }^{11-13}$ Although the majority of the clinical spectrum of this syndrome has been described, little is known about the oral status of these patients and the relationship between the genotype and phenotype, apart from the presence of a high frequency of dental aberrations, enamel hypoplasia, and hypomineralization, as well as a high prevalence of caries, in patients with $22 \mathrm{q} 11$ microdeletion. $^{14-16}$

22q11.2 DS has also been shown to be associated with developmental disturbance in dental enamel development and increased prevalence of tooth agenesis and hypodontia. ${ }^{14,16}$ These issues have traditionally been considered to be secondary effects of conditions affecting organ systems, such as CA, hypoparathyroidism, and premature birth. ${ }^{14,16}$ Moreover, other studies have shown that the disturbances of enamel are independent alterations associated with the genetic disruption itself, playing an important role in the pathogenesis of the microdeletion syndrome. ${ }^{17,18}$ The aim of this case presentation was to determine the state of gingival health and oral hygiene in patients with $22 \mathrm{q} 11.2$, as well as to perform a literature review of the dental and oral features of 22 q11 DS because of a lack of knowledge of this issue.

\section{Case Presentation}

The patients were visited at Fundación Valle de Lili Hospital to the Genetic Department in a period of time between 2016 and 2018. The oral examination was performed in the Dentistry School (UNICOC) in Cali,
Colombia by an ondotopediatric expert and two periodontic trainees. This paper describes a series of nine DG patients (four males and five females), with an average age of 9.44 Interquartile Range (IR) (IR 5-17). Medical records of 9 patients were examined and the data are extrapolated in Table 1. The extrapolated data describes the clinical characteristics of these patients including height and weight at birth Table 1. Other clinical features such as head and neck, oral cavity and other systems' involvement found in the medical records are shown in Table 2. The findings reveal the variability of the clinical spectrum of DG and highlight the high frequency of malocclusion and high susceptibility to oral infection in the patients. Additionally, hypomineralization was also observed. Of these patients, two patients with DG underwent oral examination exhibited mixed dentition. Multiple intraoral features were observed in this series, including high palate $(22 \%)$, cleft palate $(22 \%)$, bifid uvula $(11 \%)$, enamel hypomineralization and hypoplasia (22\%), dental wear $(22 \%)$, caries $(22 \%)$, and also malocclusion as the most prevalent feature $(44 \%)$. In total, seven of the nine cases showed at least one intraoral anomaly Table 2 .

\section{Case I}

Case 1 was a female patient aged 9 years old, who at 4 months after birth was diagnosed with tetralogy of Fallot and at 8 months underwent surgical correction for it. A second procedure was performed at 15 months, with the aim of correcting pulmonary stenoses. At 4 years old, the patient presented acute heart insufficiency and a clinical episode of seizures and infection. Additionally, from the age of 5 years old, the patient undertook speech therapy due to dyslexia, with special difficulty pronouncing the letters $r, j, g$, and $s$ because of velopharyngeal insufficiency.

\section{Extraoral Clinical Examination}

Soft tissues were evaluated in all patients; it was observed that the superior and inferior medial dental lines did not match the facial medial line because of deflection of

Table I Age, and Weight and Height at Birth

\begin{tabular}{|l|c|c|c|c|}
\hline & Minimum & Maximum & Mean & Standard Deviation \\
\hline Age & 5 & 17 & 9.44 & 4.275 \\
Height at birth (cm) & 42 & 51 & 48 & 2.915 \\
Weight at birth (g) & 2100 & 3350 & 2846,11 & 403,49 \\
\hline
\end{tabular}


Table 2 Clinical Variables of the Patients with DS

\begin{tabular}{|c|c|c|c|c|c|c|c|c|c|c|c|}
\hline \multicolumn{2}{|l|}{ Phenotype } & \multirow{3}{*}{$\begin{array}{l}\mathbf{I} \\
\mathrm{X}\end{array}$} & \multirow{3}{*}{$\begin{array}{l}2 \\
x\end{array}$} & \multirow{3}{*}{$\begin{array}{l}3 \\
x\end{array}$} & \multirow[t]{3}{*}{4} & \multirow[t]{3}{*}{5} & \multirow[t]{3}{*}{6} & \multirow[t]{3}{*}{7} & \multirow[b]{3}{*}{$\mathrm{X}$} & \multirow{3}{*}{$\begin{array}{l}9 \\
\times\end{array}$} & \multirow[t]{3}{*}{ \# Number of Patients with the Sign } \\
\hline Sex & & & & & & & & & & & \\
\hline & Female & & & & & & & & & & \\
\hline & Male & & & & $x$ & $x$ & $x$ & $x$ & & & \\
\hline Age (years old) & & 17 & 7 & 8 & 7 & 10 & 16 & 6 & 9 & 5 & $9.44(5-17)$ \\
\hline \multirow[t]{3}{*}{ Anthropometric } & & & & & & & & & & & \\
\hline & Height at birth & $x$ & $\mathrm{x}$ & $\mathrm{x}$ & $x$ & $x$ & $x$ & $x$ & $x$ & $x$ & $9 / 9$ \\
\hline & Weight at birth & $x$ & $\mathrm{x}$ & $\mathrm{x}$ & $x$ & $\mathrm{x}$ & $x$ & $\mathrm{x}$ & $\mathrm{x}$ & $\mathrm{x}$ & $9 / 9$ \\
\hline \multicolumn{12}{|l|}{ Head and neck } \\
\hline \multirow[t]{3}{*}{ Ears } & & & & & & & & & & & \\
\hline & Middle ear abnormalities & & & & & $\mathrm{x}$ & $x$ & & & & $2 / 9$ \\
\hline & Hearing impairment & & & & $x$ & $x$ & $x$ & & & & $3 / 9$ \\
\hline \multirow[t]{2}{*}{ Eyes } & & & & & & & & & & & \\
\hline & Short and oblique palpebral fissures & $x$ & & & & & & & & & $1 / 9$ \\
\hline \multirow[t]{3}{*}{ Nose } & & & & & & & & & & & $5 / 9$ \\
\hline & Bulbous nasal tip & & & & & $\mathrm{x}$ & & & & & $1 / 9$ \\
\hline & Filtrum defect & $x$ & & & & $x$ & & & $x$ & $x$ & $4 / 9$ \\
\hline \multirow[t]{10}{*}{ Oral cavity } & & & & & & & & & & & \\
\hline & High palate & $x$ & & & & & & & & $x$ & $2 / 9$ \\
\hline & Cleft palate & & $\mathrm{x}$ & & $x$ & & & & & & $2 / 9$ \\
\hline & Bifid uvula & & & & & & & & & $\mathrm{X}$ & $1 / 9$ \\
\hline & Enamel hypomineralization & $x$ & & & & & $x$ & & & & $2 / 9$ \\
\hline & Enamel hypoplasia & $x$ & & & & & $x$ & & & & $2 / 9$ \\
\hline & Enamel hypocalcification & $x$ & & & & & $x$ & & & & $2 / 9$ \\
\hline & Dental wear & & & & & & $x$ & & $\mathrm{X}$ & & $2 / 9$ \\
\hline & Malocclusion & & & & & $\mathrm{x}$ & $x$ & & $x$ & $x$ & $4 / 9$ \\
\hline & Caries & & & & & $\mathrm{x}$ & & & $\mathrm{x}$ & & $2 / 9$ \\
\hline \multirow[t]{3}{*}{ Cardiovascular } & & & & & & & & & & & \\
\hline & Tetralogy of Fallot & $x$ & & & & & $x$ & & $\mathrm{x}$ & $\mathrm{x}$ & $4 / 9$ \\
\hline & Right aortic arch & & & $\mathrm{x}$ & & & & & & & $1 / 9$ \\
\hline Abdomen & Inguinal hernia & & & & & $x$ & & & & & $1 / 9$ \\
\hline \multirow[t]{3}{*}{ Neurological } & Developmental delay & $x$ & $\mathrm{x}$ & $\mathrm{x}$ & $\mathrm{X}$ & & & & $x$ & & $5 / 9$ \\
\hline & Speech delay & $x$ & $x$ & $x$ & $x$ & $x$ & $x$ & & $x$ & & $7 / 9$ \\
\hline & Seizures & & & & $x$ & $x$ & $x$ & $x$ & $x$ & & $5 / 9$ \\
\hline
\end{tabular}

around $1 \mathrm{~mm}$ to the left Figure 1A and B. Other findings were also noted, such as a bicommissural line parallel with the pupillary line, narrow mouth, hypotonic upper lip, increase inferior third of the lip, dolichofacial type, concave profile, biprochelia, upper and lower anterior dental crowding, high smile, and high smile not consonant. 


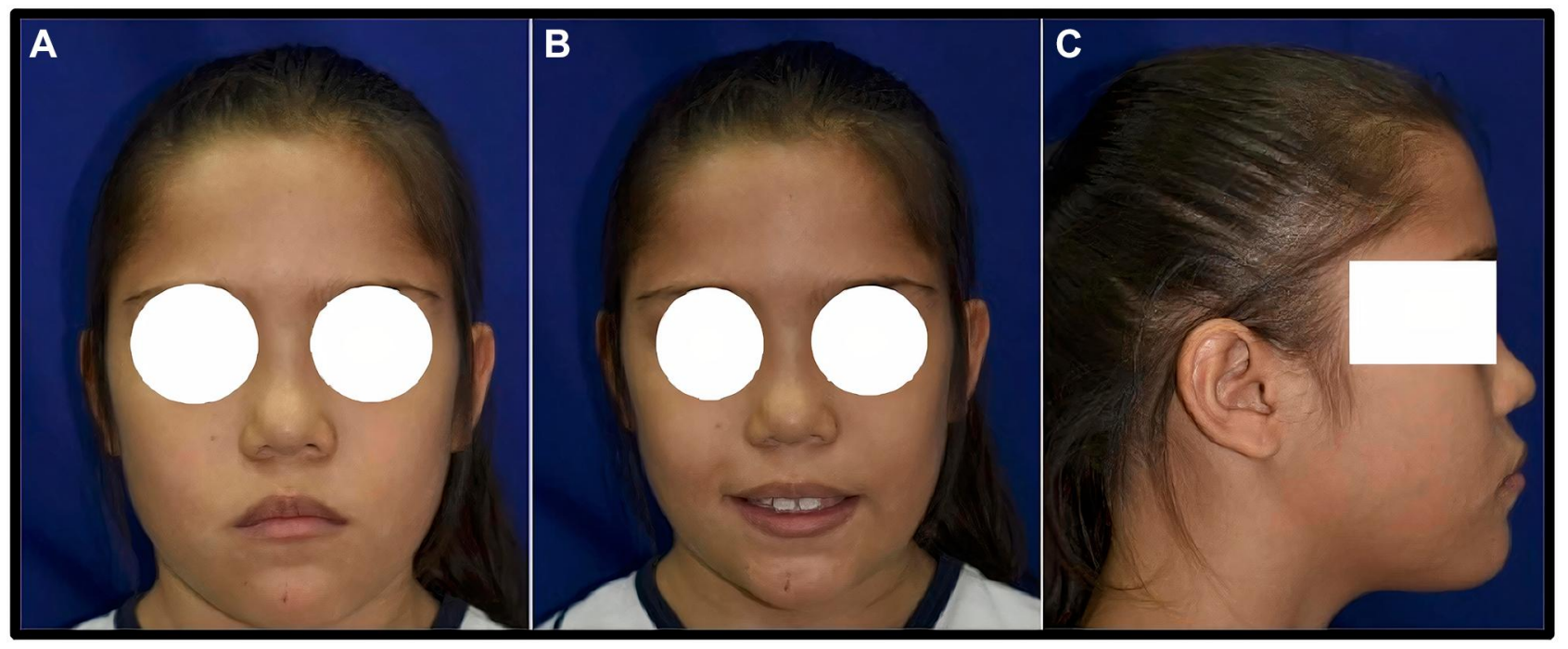

Figure I Dysmorphic phenotype in patient with DS. (A) Frontal view. (B) Smile in a frontal view. (C) Lateral view.

\section{Oral Findings}

The patient had an abnormal dental formula, with panoramic radiography showing anodontia with absence of the dental follicle in the upper right second premolar related to overlap of the maxillary incisors Figures $2 \mathrm{C}$ and B. There was also a deep bite of the mandibular incisors, along with the right side of the jaw being offset from the left Figure 1B. Additionally, there were significant changes of the color and texture of the dental tissue. Some teeth showed a granular appearance with holes in the vestibular surface of the enamel, predominantly in canines and molars Figure $1 \mathrm{~A}$ and B. Enamel hypoplasia was visualized with hypocalcification and wear of the lower incisal edges Figure 1B.

Intraoral examination showed normal oral mucosa (coral pink color) with orange flecks and appropriately

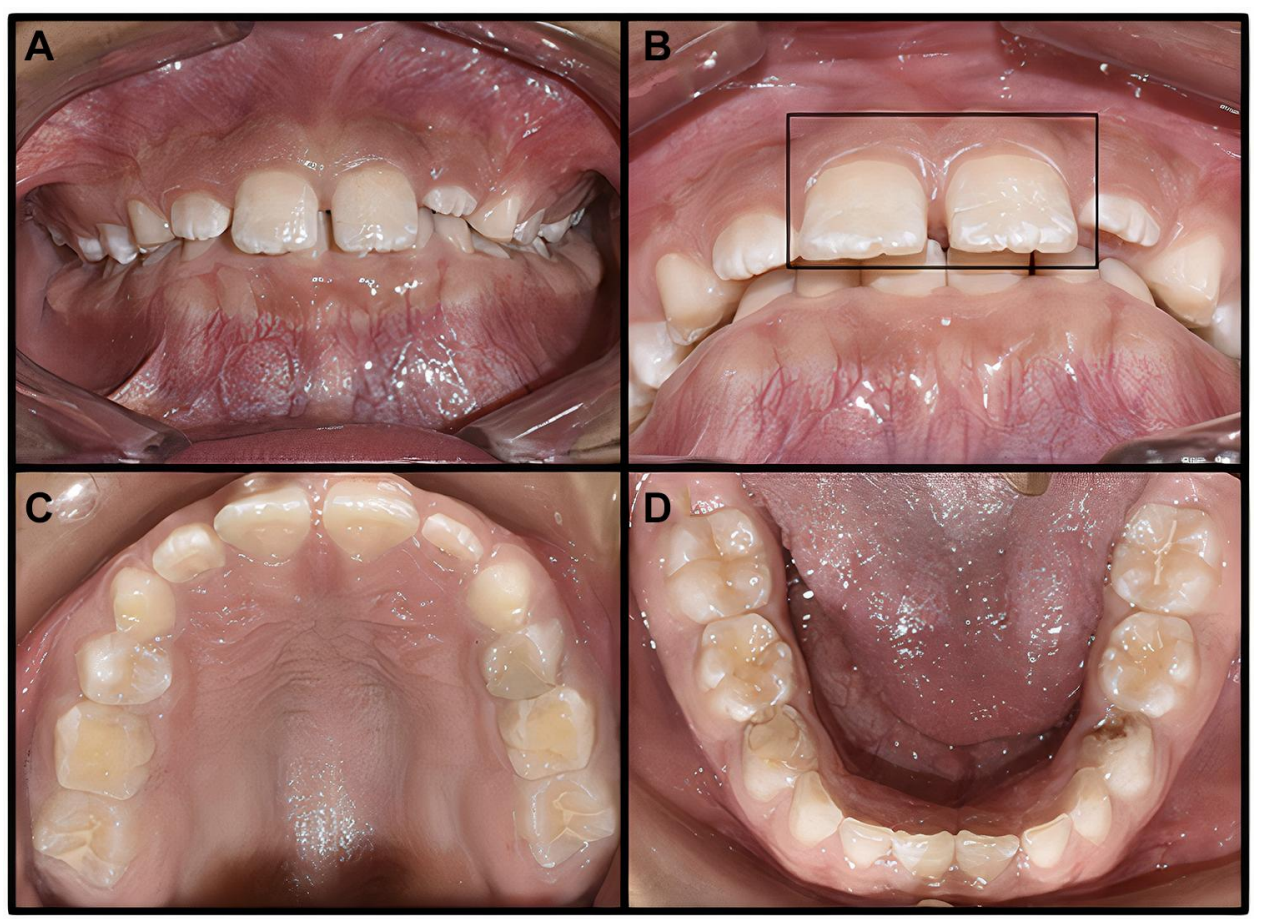

Figure 2 Dental photography. (A) Cross-bite. (B) The square in the medial incisors show enamel hypomineralization affecting both dentitions (C) superior maxillary (D) inferior maxillary, vertical overbite. 
keratinized gums, without signs of inflammation or bleeding. At the time of evaluation, the following teeth were found: upper and lower permanent incisors and first molars, as well as canines and molars. In addition, caries was identified at 74 and resin seals at 54 and 84 Figure 1A-C. The patient presented a deep bite with interdental spaces and malocclusion class II Figures 2A-D and 3.

\section{Case 2}

Case 2 was a male patient aged 16 years old. At the first month of life, he had been diagnosed with tetralogy of Fallot, which was surgically corrected. Additionally, he presented developmental delay, cognitive deficits, and velopharyngeal insufficiency. Upon physical examination, dolichocephaly was evident, with pansystolic murmur in the pulmonary area. Upon intraoral examination, malocclusion was observed, with hyperpigmentation of 11 teeth, enamel hypoplasia, amalgam restoration of the lower molars, dental crowding in the lower incisors, and apparent twisting of the upper teeth Figure 4A and B.

Finally, the results of the survey Tables 3 and 4 provided evidence matching the clinical spectrum as reported in the literature, including immune dysfunction, frequent hospitalizations, and cognitive deficits. Regarding the oral hygiene, the patients reported appropriate oral hygiene habits. The information from the different medical records is summarized in Table 2. In the majority of cases, the syndrome was diagnosed at birth due to congenital heart defect or disturbance of calcium metabolism; in the other cases, diagnosis was achieved later in development in association with poor speech and/or psychomotor development by using multiplex ligation probe amplification; the 22q11 deletion was also confirmed by fluorescence in situ hybridization testing.

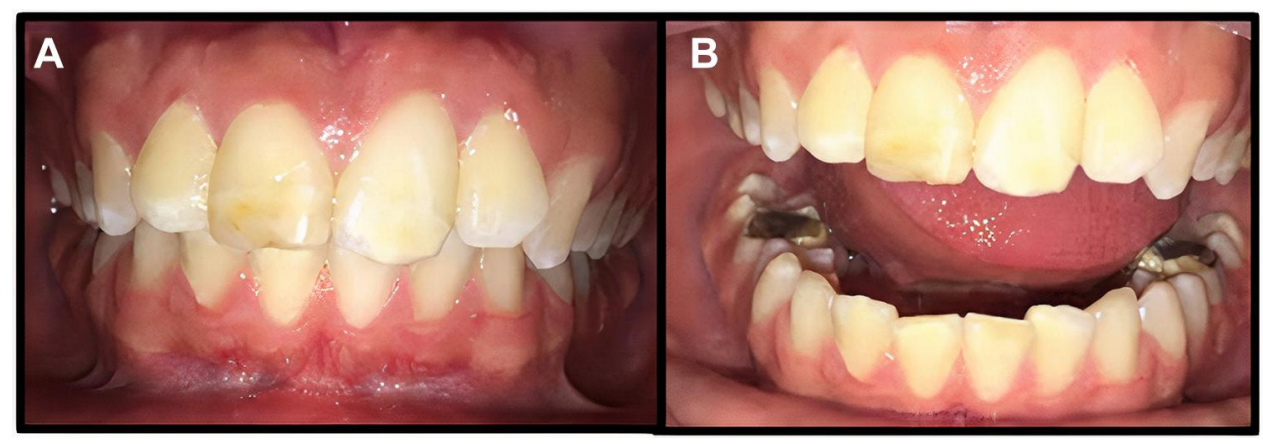

Figure 3 Dental photography (A) centric occlusion, it is evident the hyperpigmentation in the medial incisors and the generalize enamel hypoplasia. (B) Opening centric occlusion also shown the amalgam restoration of the lower molars, dental crowding in lower incisor and twisted of the upper first and second premolars.

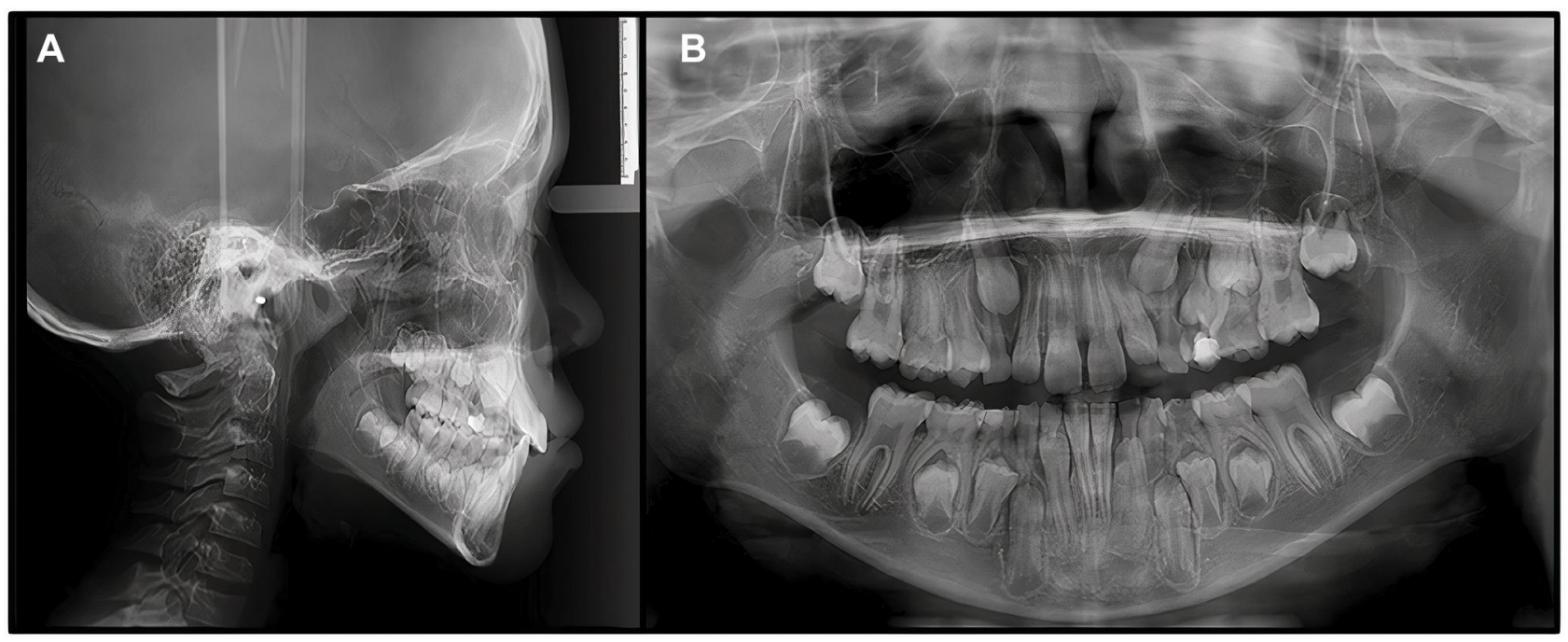

Figure 4 Panoramic dental X-ray. (A) Lateral view. (B) Panoramic dental X-ray shows dental crowding especially from the first and second superior premolars until the superior molars. 
Table 3 Results of the Survey

\begin{tabular}{|l|c|c|}
\hline & Patient I & Patient 2 \\
\hline Bruxism & No & Yes \\
\hline Symptoms of bruxism & Yes & No \\
\hline Psychiatric disorder & Yes \\
\hline Routine toothbrushing & Yes & No \\
\hline Number of toothbrushings per day & 2 & No \\
\hline Did the patient go to the dentist once a year? & No & Yes \\
\hline Cleaning and oral hygiene treatment once a year & No & Moderate \\
\hline Did the patient use dental floss once a day? & No & Moderate \\
\hline Modified Gingival Index & Moderate & Type II \\
\hline Oral Hygiene Index (OHI) & Moderate & No \\
\hline Type of malocclusion & Type II & Hypomineralization in pattern molar incisors \\
\hline Fluorosis & Yes & Yes \\
\hline Enamel defect & Yes & Yes \\
\hline Caries & Nos & \\
\hline
\end{tabular}

Abbreviation: NA, no answer.

\section{Discussion and Conclusion}

Facial characteristics associated with 22q11 microdeletion are common, and they have been clearly described in the literature, such as the presence of a retrusive lower part and a prominent upper part of the face compared with those of healthy controls. ${ }^{19,20}$ These findings were also evidenced in our cases. The facial phenotype characterized by prominent and slightly broad forehead, prominence of the midface, and retrognathia. In this series, we also show the typical features of the nose, namely, tubular nose, bulbous nasal tip, and philtrum defect associated with a narrow mouth, as also mentioned in other reports. ${ }^{19,21-25}$

Regarding dental characteristics, dental agenesis was reported in previous studies in around $15-20 \%$ of cases. ${ }^{14,19,26}$ In this series, we found a similar frequency of dental agenesis, in around $11 \%$ of cases. This is around double the level in the healthy population, in which dental agenesis has been reported to occur at a rate of around $5.5 \% .{ }^{27}$ TBX-1 is considered to play a major role in the phenotypic spectrum of the syndrome, being responsible for the dental and craniofacial features due to its role in the development of these structures. ${ }^{17,28}$

Other oral manifestations that have been reported in the literature include a high frequency of enamel defects, including hypermineralization, more often in permanent rather than temporary dentition. ${ }^{25,26}$ From our evaluation of the medical records, we found that $33 \%$ of the patients had hypomineralization and both patients who underwent oral/physical examination had hypomineralization and other dental defects. In the literature, enamel hypoplasia has been shown to be associated with heart abnormalities, ${ }^{29}$ which are common in patients with DG, and premature delivery. On the other hand, enamel hypomineralization is associated with recurrent infection, ${ }^{14}$ which might be related to immune system deficits in DG due to the thymus agenesia and also related to the higher prevalence of dental agenesia, dental eruption delay, and changes in tooth size (hypodontia) compared with those in the general population. ${ }^{15}$ It has also been described that there is a high probability of caries due to the changes in enamel and recurrent infections. ${ }^{14,30}$

Mineralization disturbances occurred in dental enamel, as well as affecting tooth shape and number of teeth; there were also eruption problems commonly associated with numerous carious lesions and gingivitis, which were also expected to be due to the underlying hypoparathyroidism and hypocalcemia. ${ }^{14,16}$ However, analyses of the damaged enamel found at rates as high 


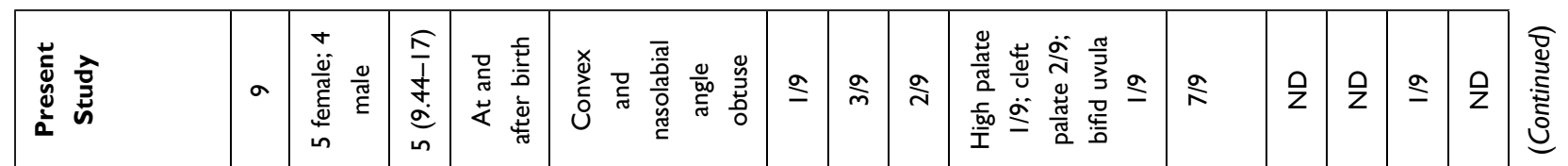

\begin{tabular}{|c|c|c|c|c|c|c|c|c|c|c|c|c|c|c|}
\hline 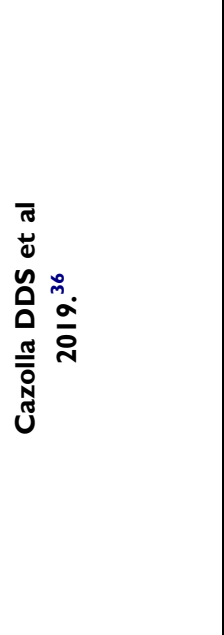 & - & 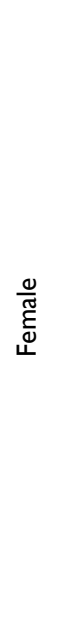 & $\sigma$ & 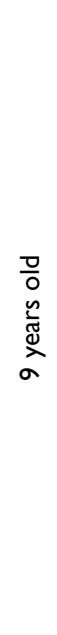 & 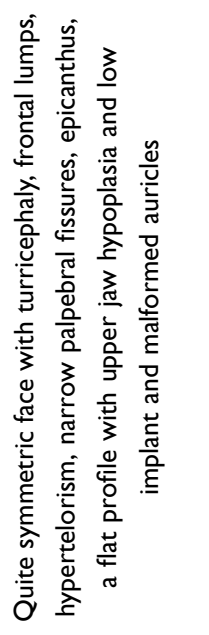 & $\Sigma$ & 口 & $\mathrm{Q}$ & 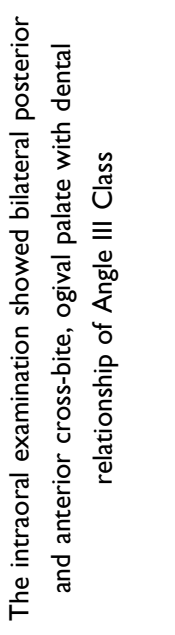 & 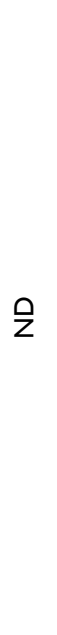 & $\bar{\delta}$ & $\bar{\delta}$ & $\bar{z}$ & $\bar{\sigma}$ \\
\hline 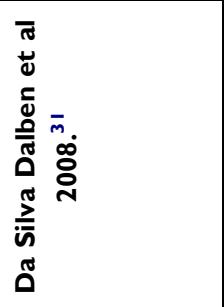 & $\stackrel{2}{\sim}$ & 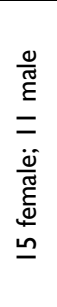 & $\begin{array}{l}0 \\
0 \\
\infty \\
\dot{d} \\
\vdots \\
a \\
\underline{\infty}\end{array}$ & $\mathrm{Q}$ & Z & 々 & १ & $\mathrm{Q}$ & 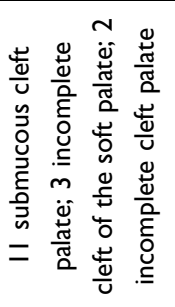 & 으 & 吕 & १ & 乙 & 乙 \\
\hline 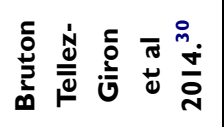 & - & $\frac{\frac{\omega}{\pi}}{\Sigma}$ & in & 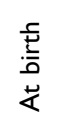 & 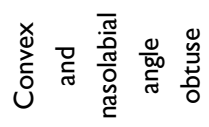 & $\Sigma$ & $\Sigma$ & $\Sigma$ & 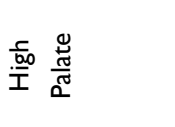 & १ & 乏 & $\bar{\delta}$ & $\bar{\delta}$ & $\bar{\delta}$ \\
\hline
\end{tabular}

站

\begin{tabular}{|c|c|c|c|c|c|c|c|c|c|c|c|c|c|c|}
\hline 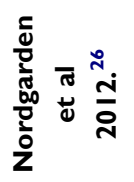 & 오 & 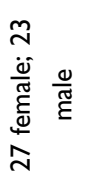 & 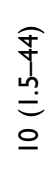 & 之 & 吕 & 乏 & $\mathrm{Q}$ & Q & 乏 & 吕 & 乏 & $\mathrm{Q}$ & 之 & 之 \\
\hline 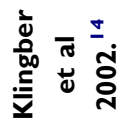 & กิ & 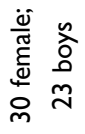 & $\underset{\infty}{\stackrel{\widehat{q}}{d}}$ & $\mathrm{Q}$ & そ & ฉ & $\mathrm{Q}$ & $\mathrm{z}$ & 乏 & 吕 & $\mathrm{Q}$ & $\frac{\mathfrak{m}}{\sigma}$ & $\mathrm{Q}$ & $\mathrm{Q}$ \\
\hline 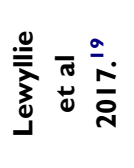 & 이 & 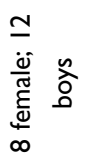 & 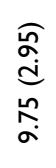 & 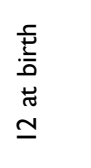 & 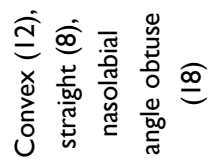 & 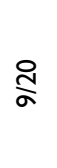 & 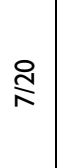 & 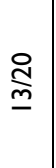 & 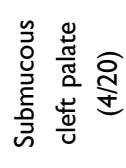 & $\mathrm{Q}$ & 吕 & $\mathrm{Q}$ & 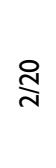 & 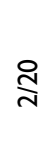 \\
\hline 可 & $\sim$ & $\frac{\frac{0}{\pi}}{\Sigma}$ & $\begin{array}{l}\frac{\widehat{m}}{1} \\
\frac{1}{2} \\
a\end{array}$ & 密壱 & 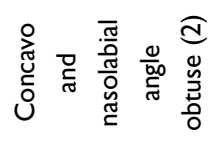 & 乏 & $\mathrm{Q}$ & 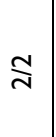 & 乏 & 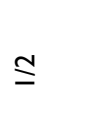 & $\stackrel{N}{\text { N }}$ & 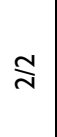 & $\mathrm{Q}$ & $\mathrm{Q}$ \\
\hline $\begin{array}{l}\frac{1}{0} \\
\frac{1}{4} \\
\dot{y}\end{array}$ & 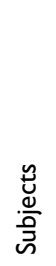 & 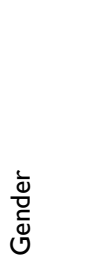 & 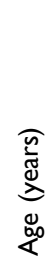 & 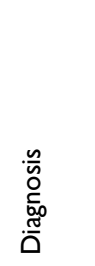 & 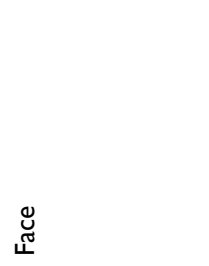 & 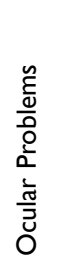 & 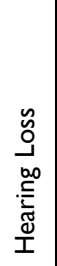 & 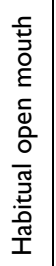 & $\begin{array}{l}\text { E } \\
\text { 志 } \\
\sum\end{array}$ & 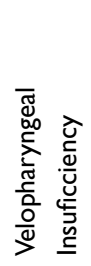 & 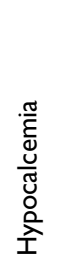 & 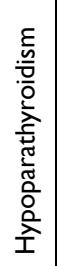 & 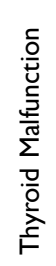 & 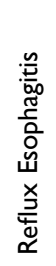 \\
\hline
\end{tabular}




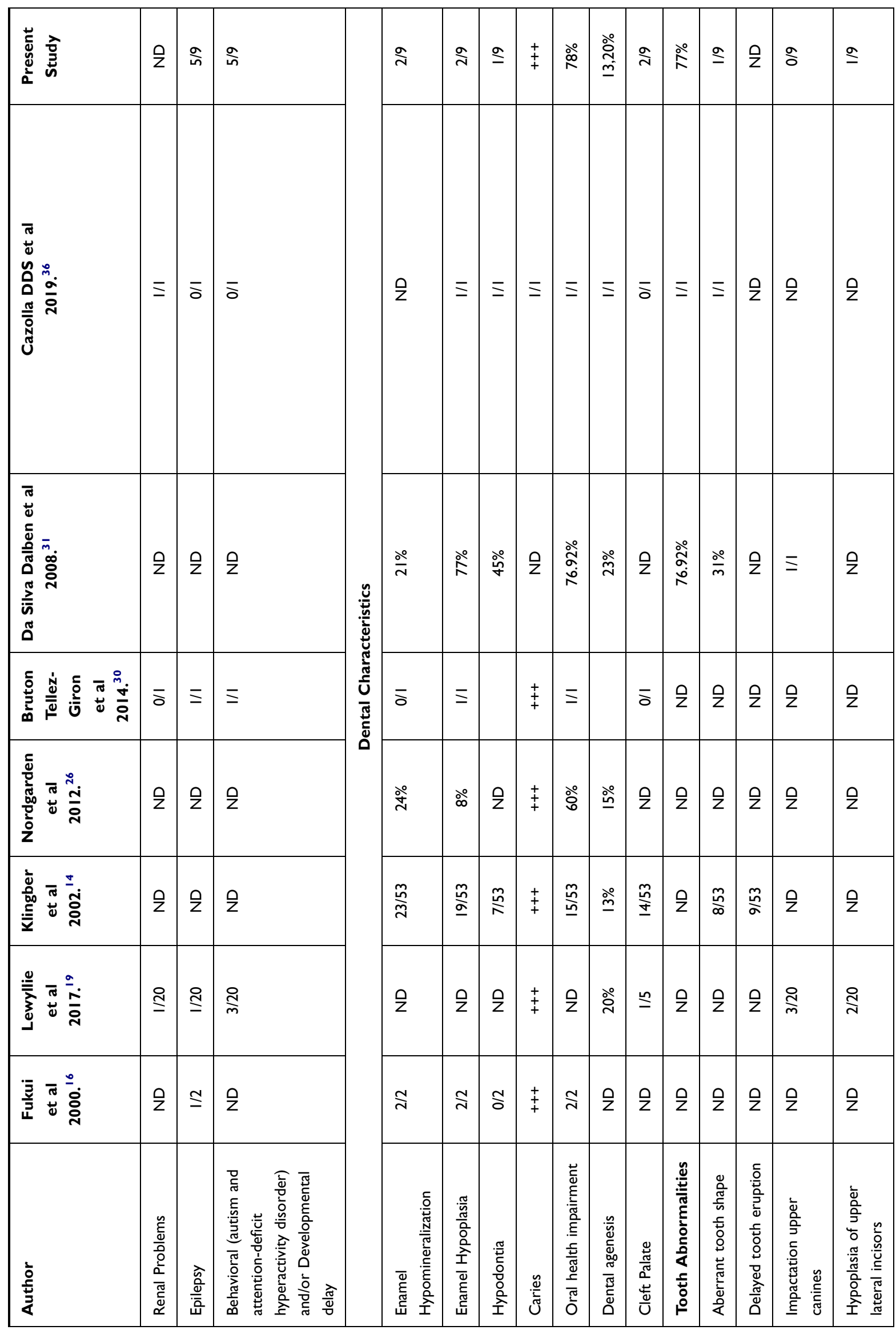




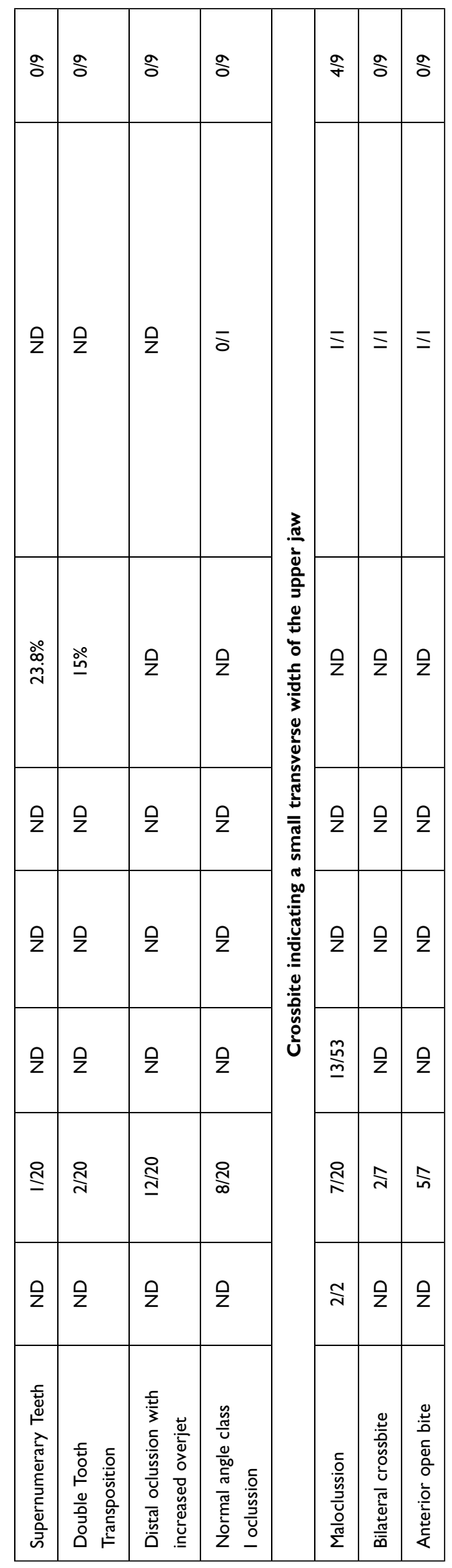

as $66 \%$ of cases, showed that the etiology differs from those in other conditions. The above-mentioned conditions are not clear causal factors of the enamel disturbances and no major correlations between the medical conditions and the changes in enamel were identified. ${ }^{26}$ Enamel defect might be caused by changes in the expression of the deleted gene(s). The candidate gene for this is TBX, the expression of which in a murine model showed that this gene is involved in creating ameloblasts during tooth development. Furthermore, a mouse model lacking functional TBX-1 exhibited hypoplasia of maxillary incisors and arrested enamel formation.

The rate of occurrence of abnormalities of teeth and soft tissue in this series was $78 \%$, similar to that reported in a previous study $(76 \%) .{ }^{31}$ By performing a TBX-1 lineage tracing experiment, it was found that this gene is related to microdontia, which coincides with a decrease in stem cell proliferation in the labial cervical cell niche (LaCL). Mice with knockout of TBX-1 showed the 22q11.2 DG phenotype in terms of oral findings such as cleft palate and craniofacial/tooth defects. ${ }^{28}$ These experiments confirmed the fundamental role of the proliferation of dental progenitors, correlating with the oral findings in different cases reported in the literature Table 4.

Malocclusion was also found in $36 \%$ of our cases, congruent with previous reports showing high frequencies of malocclusion type I (67\%) and class type II (30\% to $60 \%) .{ }^{14,19}$ Another common orofunctional disturbance associated with 22q11.2 DG is velopharyngeal insufficiency (VPI). ${ }^{32,33}$ However, in this study, VPI was not objectively evaluated. However, hypernasal speech was observed in both of the patients undergoing oral examination and submucous cleft and high palate were exhibited in $22 \%$ of the cases, at a frequency similar to that reported in other series. ${ }^{19}$

With respect to gingivitis and periodontitis, it is reported in the literature that patients with DG have a higher predisposition to these conditions because the deleted genes are involved in the process of T-lymphocyte maturation. ${ }^{34}$ In the cases presented here, we did not find any evidence of periodontium inflammation. However, in DG cases, professionals have a responsibility to provide quality oral care, given the most frequent manifestations of this disease, in order to ensure a level of oral health equal to that of the rest of the population. ${ }^{35}$

The orthopedic treatment, combined with orthodontic devices, allows the eruption of the impacted tooth and 
allows the appropriate alignment with this treatment. The crossbite correction can also be achieved, as seen in a 9 years old male with DG reported by Cazzolla et al. ${ }^{36}$ In the case of severe hyperdivergency associated with III angle skeletal class, an orthognathic surgery should be proposed at the end of the growth.

Although DG patients were shown to be genetically predisposed to periodontium diseases in the present series, there was no evidence of any specific characteristics of DG. However, the most common dental features were agenesia, enamel defects, dental crowding, and malocclusion. It is important to diagnose DG in order to implement multidisciplinary management via a familiarity with $22 q 11$ DS among those working in the field of pediatric dentistry, to overcome the frequent oral health issues found in these patients.

\section{Abbreviations}

HIRA, HIRA protein; TBX1, T-box 1 protein; COMT, Cathecol-O-methyltransferase; CRKL, Recombinant Human Crkl protein; PA, pharyngeal arches; CA, craniofacial abnormalities; DGS, DiGeorge syndrome; IR, Interquartile Range.

\section{Data Sharing Statement}

The datasets used and/or analysed during the current study are available from the corresponding author on reasonable request.

\section{Ethics Approval and Consent to Participate}

This research was conducted in accordance with the Declaration of Helsinki. The subjects and his/her parents provided written informed consent to the reporting of these cases (including the publication of images). Information revealing the subject's identity was not included in the manuscript. The patients were identified by number and not by his/her real name.

\section{Consent for Publication}

All the images and patient's material presented in this study have consented to publication and available to see upon request.

\section{Acknowledgment}

We thank the patient and his parents for agreeing to the publication of this report. We also thank the people who have contributed to this study's development and execution and Tobias Yates for his language editing.

\section{Author Contributions}

All authors made substantial contributions to conception and design, acquisition of data, or analysis and interpretation of data; took part in drafting the article or revising it critically for important intellectual content; agreed to submit to the current journal; gave final approval of the version to be published; and agree to be accountable for all aspects of the work.

\section{Funding}

All forms of support and funding for study design, data collection, data analysis and manuscript writing were provided by authors' employers (Universidad Icesi and Fundación Valle del Lili).

\section{Disclosure}

The authors have no conflicts of interest to declare.

\section{References}

1. McDonald-McGinn DM, Sullivan KE, Marino B, et al. 22q11.2 deletion syndrome. Nat Rev Dis Primer. 2015;1:15071. doi:10.1038/ nrdp.2015.71

2. Abu-Issa R, Smyth G, Smoak I, Yamamura K, Meyers EN. Fgf8 is required for pharyngeal arch and cardiovascular development in the mouse. Dev Camb Engl. 2002;129(19):4613-4625.

3. Devriendt K, Fryns JP, Mortier G, van Thienen MN, Keymolen K. The annual incidence of DiGeorge/velocardiofacial syndrome. $J$ Med Genet. 1998;35(9):789-790. doi:10.1136/jmg.35.9.789-a

4. Botto LD, May K, Fernhoff PM, et al. A population-based study of the 22q11.2 deletion: phenotype, incidence, and contribution to major birth defects in the population. Pediatrics. 2003;112(1 Pt 1):101-107. doi:10.1542/peds.112.1.101

5. Oskarsdottir S, Vujic M, Fasth A. Incidence and prevalence of the 22q11 deletion syndrome: a population-based study in Western Sweden. Arch Dis Child. 2004;89(2):148-151. doi:10.1136/adc.2003.026880

6. Grati FR, Molina Gomes D, Ferreira JCPB, et al. Prevalence of recurrent pathogenic microdeletions and microduplications in over 9500 pregnancies. Prenat Diagn. 2015;35(8):801-809. doi:10.1002/ pd. 4613

7. Demily C, Rossi M, Schneider M, et al. Perspectives actuelles dans la microdélétion 22q11.2: prise en charge du phénotype neurocomportemental. L'Encéphale. 2015;41(3):266-273. doi:10.1016/j.encep.2014.10.005

8. Farrell MJ, Stadt H, Wallis KT, et al. HIRA, a DiGeorge syndrome candidate gene, is required for cardiac outflow tract septation. Circ Res. 1999;84(2):127-135. doi:10.1161/01.res.84.2.127

9. Scambler PJ. 22q11 deletion syndrome: a role for TBX1 in pharyngeal and cardiovascular development. Pediatr Cardiol. 2010;31 (3):378-390. doi:10.1007/s00246-009-9613-0

10. Dauvilliers Y, Tafti M, Landolt HP. Catechol-O-methyltransferase, dopamine, and sleep-wake regulation. Sleep Med Rev. 2015;22:47-53. doi:10.1016/j.smrv.2014.10.006

11. Ryan AK, Goodship JA, Wilson DI, et al. Spectrum of clinical features associated with interstitial chromosome 22q11 deletions: a European collaborative study. J Med Genet. 1997;34(10):798-804. doi:10.1136/jmg.34.10.798 
12. Emanuel BS, McDonald-McGinn D, Saitta SC, Zackai EH. The 22q11.2 deletion syndrome. Adv Pediatr. 2001;48:39-73.

13. Yagi H, Furutani Y, Hamada H, et al. Role of TBX1 in human del22q11.2 syndrome. Lancet. 2003;362(9393):1366-1373. doi:10.1016/s0140-6736(03)14632-6

14. Klingberg G, Oskarsdóttir S, Johannesson EL, Norén JG. Oral manifestations in 22q11 deletion syndrome. Int J Paediatr Dent. 2002;12 (1):14-23.

15. Klingberg G, Dietz W, Óskarsdóttir S, Odelius H, Gelander L, Norén JG. Morphological appearance and chemical composition of enamel in primary teeth from patients with $22 \mathrm{q} 11$ deletion syndrome. Eur J Oral Sci. 2005;113(4):303-311. doi:10.1111/j.16000722.2005.00223.x

16. Fukui N, Amano A, Akiyama S, Daikoku H, Wakisaka S, Morisaki I. Oral findings in DiGeorge syndrome: clinical features and histologic study of primary teeth. Oral Surg Oral Med Oral Pathol Oral Radiol Endod. 2000;89(2):208-215. doi:10.1067/moe.2000.103884

17. Mitsiadis TA, Tucker AS, De Bari C, Cobourne MT, Rice DPC. A regulatory relationship between $\mathrm{Tbx} 1$ and FGF signaling during tooth morphogenesis and ameloblast lineage determination. Dev Biol. 2008;320(1):39-48. doi:10.1016/j.ydbio.2008.04.006

18. Catón J, Luder H-U, Zoupa M, et al. Enamel-free teeth: tbx 1 deletion affects amelogenesis in rodent incisors. Dev Biol. 2009;328 (2):493-505. doi:10.1016/j.ydbio.2009.02.014

19. Lewyllie A, Roosenboom J, Indencleef K, et al. A comprehensive Craniofacial Study of 22q11.2 deletion syndrome. J Dent Res. 2017;96(12):1386-1391. doi:10.1177/0022034517720630

20. Prasad S, Katina S, Hennessy RJ, Murphy KC, Bowman AW, Waddington JL. Craniofacial dysmorphology in 22q11.2 deletion syndrome by $3 \mathrm{D}$ laser surface imaging and geometric morphometrics: illuminating the developmental relationship to risk for psychosis. $\mathrm{Am}$ $J$ Med Genet A. 2015;167A(3):529-536. doi:10.1002/ajmg.a.36893

21. Swillen A, Vogels A, Devriendt K, Fryns JP. Chromosome 22q11 deletion syndrome: update and review of the clinical features, cognitive-behavioral spectrum, and psychiatric complications. $A m$ $J$ Med Genet. 2000;97(2):128-135. doi:10.1002/1096-8628(200022) 97:2<128::aid-ajmg4>3.0.co;2-z

22. Shprintzen RJ. Velo-cardio-facial syndrome: 30 years of study. Dev Disabil Res Rev. 2008;14(1):3-10. doi:10.1002/ddrr.2

23. Butts SC. The facial phenotype of the velo-cardio-facial syndrome. Int J Pediatr Otorhinolaryngol. 2009;73(3):343-350. doi:10.1016/j. ijporl.2008.10.011

24. Cancrini C, Puliafito P, Digilio MC, et al. Clinical features and follow-up in patients with 22q11.2 deletion syndrome. J Pediatr. 2014;164(6):1475-1480.e2. doi:10.1016/j.jpeds.2014.01.056

25. Hacıhamdioğlu B, Hacıhamdioğlu D, Delil K. 22q11 deletion syndrome: current perspective. Appl Clin Genet. 2015;8:123-132. doi:10.2147/TACG.S82105
26. Nordgarden H, Lima K, Skogedal N, Følling I, Storhaug K, Abrahamsen TG. Dental developmental disturbances in 50 individuals with the 22q11.2 deletion syndrome; relation to medical conditions? Acta Odontol Scand. 2012;70(3):194-201. doi:10.3109/ 00016357.2011.629624

27. Polder BJ, Van't Hof MA, Fpgm VDL, Kuijpers-Jagtman AM. A meta-analysis of the prevalence of dental agenesis of permanent teeth. Community Dent Oral Epidemiol. 2004;32(3):217-226. doi:10.1111/j.1600-0528.2004.00158.x

28. Gao S, Moreno M, Eliason S, et al. TBX1 protein interactions and microRNA-96-5p regulation controls cell proliferation during craniofacial and dental development: implications for 22q11.2 deletion syndrome. Hum Mol Genet. 2015;24(8):2330-2348. doi:10.1093/ $\mathrm{hmg} / \mathrm{ddu} 750$

29. Cruvinel VRN, Gravina DBL, Azevedo TDPL, Rezende CSD, Bezerra ACB, Toledo OAD. Prevalence of enamel defects and associated risk factors in both dentitions in preterm and full term born children. J Appl Oral Sci. 2012;20(3):310-317. doi:10.1590/S167877572012000300003

30. Butrón Téllez GC, Hernández-Zeni DV, Ruíz-Rodríguez MDS, Rosales-Berber MÁ. Manejo estomatológico de un paciente con Síndrome de Di-George. Reporte de un caso. Odontol Pediatr Lima. 2014;149-154.

31. da Silva Dalben G, Richieri-Costa A, de Assis Taveira LA. Tooth abnormalities and soft tissue changes in patients with velocardiofacial syndrome. Oral Surg Oral Med Oral Pathol Oral Radiol Endod. 2008;106(2):e46-e51. doi:10.1016/j.tripleo.2008.04.019

32. Persson C, Lohmander A, Jönsson R, Oskarsdóttir S, Söderpalm E. A prospective cross-sectional study of speech in patients with the 22q11 deletion syndrome. J Commun Disord. 2003;36(1):13-47. doi:10.1016/s0021-9924(02)00133-8

33. Ysunza A, Chaiyasate K, Micale MA, et al. 22q11.2 deletion detected by endoscopic observation of pharyngeal pulsations in a child with submucous cleft palate and persistent velopharyngeal insufficiency. Int $J$ Pediatr Otorhinolaryngol. 2014;78(10):1789-1794. doi:10.1016/j.ijporl.2014.07.027

34. Toka O, Karl M, Dittrich S, Holst S, Holst A. Dental aspects in patients with DiGeorge syndrome. Quintessence Int. 2010;41:7.

35. Klingberg G, Hallberg U, Oskarsdóttir S. Oral health and 22q11 deletion syndrome: thoughts and experiences from the parents' perspectives. Int J Paediatr Dent. 2010;20(4):283-292. doi:10.1111/ j.1365-263X.2010.01052.x

36. Cazzolla AP, Lacaita MG, Lacarbonara V, et al. Orthopedic and orthodontic management in a patient with DiGeorge syndrome and familial Mediterranean fever: a case report. Spec Care Dent off Publ Am Assoc Hosp Dent Acad Dent Handicap Am Soc Geriatr Dent. 2019;39(3):340-347. doi:10.1111/scd.12381

\section{Publish your work in this journal}

The Application of Clinical Genetics is an international, peerreviewed open access journal that welcomes laboratory and clinical findings in the field of human genetics. Specific topics include: Population genetics; Functional genetics; Natural history of genetic disease; Management of genetic disease; Mechanisms of genetic disease;
Counselling and ethical issues; Animal models; Pharmacogenetics; Prenatal diagnosis; Dysmorphology. The manuscript management system is completely online and includes a very quick and fair peerreview system, which is all easy to use. Visit http://www.dovepress. com/testimonials.php to read real quotes from published authors. 